\title{
Socioeconomic Patterns of COVID-19 Clusters in Low-Incidence City, Hong Kong
}

Gary K.K. Chung, Siu-Ming Chan, Yat-Hang Chan, Jean Woo, Hung Wong, Samuel Y. Wong, Eng Kiong Yeoh, Michael Marmot, Roger Y. Chung

Although coronavirus disease (COVID-19) outbreaks have been relatively well controlled in Hong Kong, containment remains challenging among socioeconomically disadvantaged persons. They are at higher risk for widespread COVID-19 transmission through sizable clustering, probably because of exposure to social settings in which existing mitigation policies had differential socioeconomic effects.

A S coronavirus disease (COVID-19) continued to spread globally, studies of transmission mainly focused on clusters of $\geq 2$ epidemiologically linked cases. Some governments, including those of New Zealand and Hong Kong, China, put specific focus on sizable infection clusters (i.e., clusters of $\geq 10$ epidemiologically linked case-patients who are not all part of the same household) to detect widespread human-to-human COVID-19 infections with potentially greater numbers of successive transmission generations $(1,2)$. These sizable infection clusters are closely linked to COVID-19 superspreading; as many as 7 superspreading events were related to the first few sizable infection clusters in Hong Kong (3). Given the widely observed higher COVID-19 incidence associated with socioeconomic disadvantages (4-7), determining whether the risk for sizable infection clustering is socioeconomically patterned is of public health significance. Such a pattern would imply not only higher risk for exposure to the virus but also increased risk of spreading the disease among socioeconomically disadvantaged communities.

Unlike many other parts of the world, Hong Kong has had a relatively low COVID-19 incidence,

Author affiliations: The Chinese University of Hong Kong, Hong Kong, China (G.K.K. Chung, S.-M. Chan, Y.-H. Chan, J. Woo, H. Wong, S.Y. Wong, E.K. Yeoh, M. Marmot, R.Y. Chung); City University of Hong Kong, Hong Kong (S.-M. Chan); University College London, London, UK (M. Marmot)

DOI: https://doi.org/10.3201/eid2711.204840 which made comprehensive contact tracing to identify sizable infection clusters possible and meaningful. In this study, we examined the association of socioeconomic position with sizable infection clustering in Hong Kong and explored the potential heterogeneity by case classification and different activity categories of clusters. For this study, we used data collected by the Centre for Health Protection (CHP), the Planning Department, and the Census and Statistics Department of the Hong Kong Government in compliance with the Declaration of Professional Ethics of the International Statistical Institute.

\section{The Study}

We collected data on individual laboratory-confirmed cases from CHP (1) and a COVID-19 information website (8), which shows compiled information released by the CHP. During January 23-October 31, 2020, a total of 5,324 cases and 30 sizable infection clusters were identified (Appendix Table 1, https:/ / wwwnc.cdc.gov/EID/article/27/11/20-4840-App1. pdf). We included 3,587 local cases with recognizable residential addresses in this study; 778 of those cases were linked to sizable infection clusters (Table 1).

We assigned as the dependent variable whether a case belonged to a sizable infection cluster. These sizable infection cluster cases included the earliest identified unlinked source cases and their subsequent epidemiologically linked cases. We categorized these clusters as living, working, dining, or entertainment (>100 cases each) on the basis of the type of activities most closely associated with the venues at which the source cases of each corresponding cluster were identified.

We adopted self-reported residential addresses of the confirmed case-patients (8) to generate 2 proxy socioeconomic measures (Appendix). First, we calculated the area-level income poverty rates as the proportion of households living at $<50 \%$ of the median 
Table 1. Characteristics of local coronavirus disease case-patients with a valid residential address, Hong Kong, 2020*

\begin{tabular}{|c|c|c|c|c|c|}
\hline \multirow[b]{2}{*}{ Characteristic } & \multirow{2}{*}{$\begin{array}{l}\text { Total sample, } \mathrm{N} \\
=3,587\end{array}$} & \multicolumn{4}{|c|}{ Area-level income poverty rate $\dagger$} \\
\hline & & 1st quartile & 2nd quartile & 3rd quartile & 4th quartile \\
\hline Mean age, y (SD) & $47.92(19.96)$ & $44.20(19.17)$ & $47.66(18.65)$ & $49.93(20.86)$ & $46.63(19.60)$ \\
\hline \multicolumn{6}{|l|}{ Sex } \\
\hline M & $1,750(48.8)$ & $158(51.6)$ & $348(47.4)$ & $712(50.6)$ & $532(46.6)$ \\
\hline $\mathrm{F}$ & $1,837(51.2)$ & $148(48.4)$ & $386(52.6)$ & $694(49.4)$ & $609(53.4)$ \\
\hline \multicolumn{6}{|l|}{ Sizable infection clustering } \\
\hline Noncluster cases & $2,809(78.3)$ & 275 (89.9) & $617(84.1)$ & $1,033(73.5)$ & $884(77.5)$ \\
\hline Cluster cases $\ddagger$ & $778(21.7)$ & $31(10.1)$ & $117(15.9)$ & $373(26.5)$ & $257(22.5)$ \\
\hline Living clusters & $159(4.4)$ & $0(0.0)$ & $3(0.4)$ & $99(7.0)$ & $57(5.0)$ \\
\hline Working clusters & $225(6.3)$ & $8(2.6)$ & $42(5.7)$ & $77(5.5)$ & $98(8.6)$ \\
\hline Dining clusters & $248(6.9)$ & $15(4.9)$ & $35(4.8)$ & $137(9.7)$ & $61(5.3)$ \\
\hline Entertainment clusters & $114(3.2)$ & $8(2.6)$ & $27(3.7)$ & $48(3.4)$ & $31(2.7)$ \\
\hline Others $\S$ & $33(0.9)$ & $1(0.3)$ & $10(1.4)$ & $12(0.9)$ & $10(0.9)$ \\
\hline \multicolumn{6}{|l|}{ Case classification } \\
\hline Infection source cases & $1,455(40.6)$ & $133(43.5)$ & $317(43.2)$ & $528(37.6)$ & $477(41.8)$ \\
\hline Probable local cases & $95(2.6)$ & $29(9.5)$ & $31(4.2)$ & $24(1.7)$ & $11(1.0)$ \\
\hline Local cases & $1,360(37.9)$ & $104(34.0)$ & $286(39.0)$ & $504(35.8)$ & $466(40.8)$ \\
\hline $\begin{array}{l}\text { Cases epidemiologically linked to } \\
\text { infection source cases }\end{array}$ & $2,132(59.4)$ & $173(56.5)$ & $417(56.8)$ & $878(62.4)$ & $664(58.2)$ \\
\hline Linked to probable local cases & $62(1.7)$ & $12(3.9)$ & $20(2.7)$ & $22(1.6)$ & $8(0.7)$ \\
\hline Linked to local cases & $2,070(57.7)$ & $161(52.6)$ & $397(54.1)$ & $856(60.9)$ & $656(57.5)$ \\
\hline \multicolumn{6}{|l|}{ Presence of symptoms } \\
\hline Asymptomatic & $590(16.4)$ & $44(14.4)$ & $89(12.1)$ & $262(18.6)$ & $195(17.1)$ \\
\hline Symptomatic & $2,997(83.6)$ & $262(85.6)$ & $645(87.9)$ & $1144(81.4)$ & $946(82.9)$ \\
\hline \multicolumn{6}{|l|}{ Type of housing } \\
\hline Public rental housing & $1,479(41.2)$ & $6(2.0)$ & $243(33.1)$ & $591(42.0)$ & $639(56.0)$ \\
\hline Subsidized home ownership & $409(11.4)$ & $6(2.0)$ & $137(18.7)$ & $171(12.2)$ & $95(8.3)$ \\
\hline Private housing & $1,377(38.4)$ & $261(85.3)$ & $307(41.8)$ & $469(33.4)$ & $340(29.8)$ \\
\hline Residential care homes & $116(3.2)$ & $3(1.0)$ & $6(0.8)$ & $86(6.1)$ & $21(1.8)$ \\
\hline Other & $206(5.7)$ & $30(9.8)$ & $41(5.6)$ & $89(6.3)$ & $46(4.0)$ \\
\hline \multicolumn{6}{|l|}{ Area-level population density\# } \\
\hline 1st quartile & $409(11.4)$ & $82(26.8)$ & $165(22.5)$ & $102(7.3)$ & $60(5.3)$ \\
\hline 2nd quartile & $752(21.0)$ & $91(29.7)$ & $177(24.1)$ & $275(19.6)$ & $209(18.3)$ \\
\hline 3rd quartile & $888(24.8)$ & $55(18.0)$ & $200(27.2)$ & $310(22.0)$ & $323(28.3)$ \\
\hline 4th quartile & $1,538(42.9)$ & $78(25.5)$ & $192(26.2)$ & $719(51.1)$ & $549(48.1)$ \\
\hline \multicolumn{6}{|c|}{$\begin{array}{l}\text { *Values are no. (\%) except as indicated. We used data current to October } 31,2020 . \\
\text { †The } 1 \text { st quartile is the wealthiest group and } 4 \text { th quartile the poorest group. } \\
\text { tThe number of cluster cases differed from the sum of cluster cases across cluster types because one case was involved in both dining and working } \\
\text { clusters. } \\
\text { §Traveling, religious, grocery shopping activities. } \\
\text { \#The 1st quartile is lowest population density and 4th quartile the highest density. }\end{array}$} \\
\hline
\end{tabular}

monthly household income for the corresponding household size in each of the 154 small-area Tertiary Planning Units (9); we then grouped these rates into quartiles. Second, we categorized the individual-level housing type into public rental housing, subsidized home ownership, private housing, residential care homes, and others (e.g., villages, industrial and commercial buildings, and staff quarters).

Results of multilevel binary logistic regression with random intercepts at area level showed that case-patients living in the wealthiest areas (i.e., 1st quartile) were $65 \%$ less likely to be cases in sizable infection clusters (adjusted OR [aOR] 0.35, 95\% CI 0.19-0.65) than those living in the poorest areas (i.e., 4 th quartile), after adjusting for confounding factors (Table 2). Area-level socioeconomic patterns of sizable clustering were more apparent among casepatients epidemiologically linked to previously confirmed cases (aOR 0.34, 95\% CI 0.18-0.66) than among unlinked source cases (aOR 0.61, 95\% CI 0.19-1.97). Such patterns were more pronounced for those in living and working clusters than in dining and entertainment clusters. At the individual level, persons living in residential care homes tended to be part of living-related sizable infection clusters. We observed stark variations in the effect of private housing across cluster categories; case-patients living in private housing had lower odds of being in working clusters (aOR $0.66,95 \%$ CI .45-0.96) but increased odds of being in entertainment clusters (aOR 3.20, 95\% CI 1.795.72) compared with case-patients living in public rental housing.

\section{Conclusions}

This study showed that socioeconomic disadvantage was associated with a wider COVID-19 transmission in the form of sizable infection clustering regardless of epidemic waves (Appendix Table 2); we observed a 
stronger socioeconomic pattern in clusters of more essential activities (i.e., living and working) than in clusters of less essential activities (i.e., dining and entertainment). The more apparent socioeconomic pattern of sizable COVID-19 clustering among epidemiologically linked cases suggested that the socioeconomically disadvantaged were not necessarily more prone to contracting the disease from random infection sources but that, once they contracted the disease, their communities were at higher risk for wide transmission of disease.

The stringent social distancing policies imposed by the Hong Kong government seriously disrupted social activities and confined residents to their own homes or local communities. The socioeconomically disadvantaged are particularly likely to be infected if they live in small, overcrowded apartments with poorer ventilation $(10,11)$. Residential-care homes constituted 6 of 7 living-related infection clusters; these care homes tend to be located in socioeconomically disadvantaged areas, and sizable infection clusters involving care homes started to form when community outbreaks of local transmission became severe in early July 2020 $(1,12)$. This observation implies that residential care home clusters are usually not only sporadic but also possibly concomitant with an outbreak in the disadvantaged community (13).
Work arrangement is another major COVID-19 containment measure with differential socioeconomic impacts. Despite advocacy for the work-from-home arrangement, the socioeconomically disadvantaged often could hardly benefit from this option (5). These persons also tend to work in occupations demanding longer hours and more intense social interactions and rely heavily on public transport, which inevitably increased their risk of having contact with infected persons and subsequently spreading the disease within their community. Moreover, the lack of financial subsidies to confirmed case-patients before late November 2020 may have kept these workers or the selfemployed, who had no paid sick leave, from opting for necessary COVID-19 testing, thereby hampering early transmission containment. Altogether, we were not surprised to see several sizable infection clusters in the construction, transport, and direct-selling industries in Hong Kong.

Our results shed light on the pervasive social inequalities deeply entrenched in society. The socioeconomically disadvantaged have limited resources and opportunities to overcome structural constraints of the social environment (14) and are the ones hardest hit in emergencies or adverse events. The wealthier groups are at risk for infection through entertainment activities, given the propensity for widespread

\begin{tabular}{|c|c|c|c|c|c|c|c|}
\hline \multirow[b]{3}{*}{ Category } & \multicolumn{7}{|c|}{ aOR $(95 \% \mathrm{Cl}) \dagger$} \\
\hline & \multirow{2}{*}{$\begin{array}{c}\text { Total } \\
\text { samples } \ddagger\end{array}$} & \multicolumn{2}{|c|}{ Case classification } & \multicolumn{4}{|c|}{ Specific activity categories $\ddagger$} \\
\hline & & Unlinked $\ddagger$ & Linked $\ddagger$ & Living§ & Working§ & Dining§ & Entert \\
\hline \multicolumn{8}{|c|}{ Area-level income poverty rate } \\
\hline 4th quartile & Referent & Referent & Referent & Referent & Referent & Referent & Referent \\
\hline 3rd quartile & $\begin{array}{c}0.89 \\
(0.58-1.37)\end{array}$ & $\begin{array}{c}1.27 \\
(0.73-2.19)\end{array}$ & $\begin{array}{c}0.81 \\
(0.50-1.29)\end{array}$ & $\begin{array}{c}0.61 \\
(0.14-2.71)\end{array}$ & $\begin{array}{c}0.83 \\
(0.46-1.49)\end{array}$ & $\begin{array}{c}1.00 \\
(0.55-1.81)\end{array}$ & $\begin{array}{c}1.13 \\
(0.54-2.34)\end{array}$ \\
\hline 2nd quartile & $\begin{array}{c}0.67 \\
(0.42-1.06)\end{array}$ & $\begin{array}{c}0.85 \\
(0.42-1.74)\end{array}$ & $\begin{array}{c}0.64 \\
(0.39-1.07)\end{array}$ & $\begin{array}{c}0.18 \\
(0.02-1.52)\end{array}$ & $\begin{array}{c}0.70 \\
(0.37-1.34)\end{array}$ & $\begin{array}{c}0.82 \\
(0.43-1.56)\end{array}$ & $\begin{array}{c}0.92 \\
(0.42-2.06)\end{array}$ \\
\hline 1st quartile & $\begin{array}{c}0.35 \\
(0.19-0.65)\end{array}$ & $\begin{array}{c}0.61 \\
(0.19-1.97)\end{array}$ & $\begin{array}{c}0.34 \\
(0.18-0.66)\end{array}$ & NA\# & $\begin{array}{c}0.33 \\
(0.13-0.87)\end{array}$ & $\begin{array}{c}0.85 \\
(0.37-1.92)\end{array}$ & $\begin{array}{c}0.47 \\
(0.16-1.35)\end{array}$ \\
\hline \multicolumn{8}{|c|}{ Individual-level housing type } \\
\hline $\begin{array}{l}\text { Public rental } \\
\text { housing }\end{array}$ & Referent & Referent & Referent & Referent & Referent & Referent & Referent \\
\hline Subsidized home & 0.97 & 1.26 & 0.99 & 1.22 & 0.72 & 1.06 & 1.27 \\
\hline ownership & $(0.72-1.31)$ & $(0.63-2.52)$ & $(0.69-1.40)$ & $(0.33-4.49)$ & $(0.44-1.17)$ & $(0.70-1.59)$ & $(0.53-3.06)$ \\
\hline Private housing & $\begin{array}{c}0.99 \\
(0.77-1.26)\end{array}$ & $\begin{array}{c}0.86 \\
(0.49-1.51)\end{array}$ & $\begin{array}{c}1.05 \\
(0.79-1.39)\end{array}$ & $\begin{array}{c}1.12 \\
(0.46-2.72)\end{array}$ & $\begin{array}{c}0.66 \\
(0.45-0.96)\end{array}$ & $\begin{array}{c}0.90 \\
(0.62-1.32)\end{array}$ & $\begin{array}{c}3.20 \\
(1.79-5.72)\end{array}$ \\
\hline $\begin{array}{l}\text { Residential care } \\
\text { homes }\end{array}$ & $\begin{array}{c}27.20 \\
(14.16-52.26)\end{array}$ & $\begin{array}{c}4.69 \\
(0.88-24.97)\end{array}$ & $\begin{array}{c}22.35 \\
(10.00-49.96)\end{array}$ & $\begin{array}{c}720.16 \\
(224.14- \\
2,313.84)\end{array}$ & $N A^{* *}$ & NA\# & NA\# \\
\hline Other & $\begin{array}{c}0.82 \\
(0.51-1.33)\end{array}$ & $\begin{array}{c}0.70 \\
(0.22-2.27)\end{array}$ & $\begin{array}{c}0.84 \\
(0.49-1.46) \\
\end{array}$ & $\begin{array}{c}3.34 \\
(0.87-12.81)\end{array}$ & $\begin{array}{c}1.03 \\
(0.53-1.99) \\
\end{array}$ & $\begin{array}{c}0.27 \\
(0.09-0.82) \\
\end{array}$ & $\begin{array}{c}1.90 \\
(0.71-5.09) \\
\end{array}$ \\
\hline \multicolumn{8}{|c|}{ 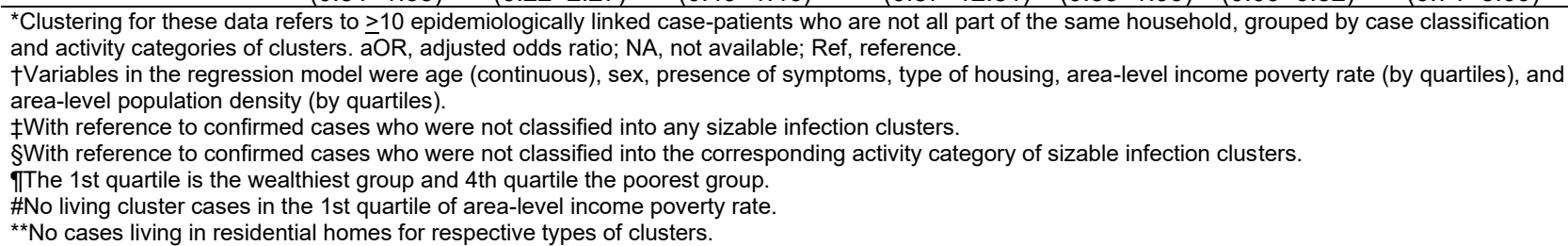 } \\
\hline
\end{tabular}


dispersion and difficulty in COVID-19 containment in these settings (15). Infection control may thus work better for the wealthier groups through restriction of entertainment activities.

A limitation of this study lies in the potential residual confounding as a result of the limited information the CHP released on the confirmed cases. In addition, case-patients who experienced symptoms after COVID-19 diagnosis may have been misclassified as asymptomatic. Moreover, we categorized the sizable infection clusters by social activities; therefore, infected case-patients epidemiologically linked to the source of one cluster were classified into the same activity category of the cluster regardless of their involvement with the specific activities.

In summary, despite relatively low COVID-19 incidence in Hong Kong, transmission containment among socioeconomically disadvantaged persons and communities remains challenging. Consideration of social inequalities is crucial to deploying equitable containment and exit strategies.

\section{Acknowledgments}

We thank the team from the COVID-19 in HK (https://covid19.vote4.hk) online platform for integrating and extracting information on residential addresses of all infected cases in Hong Kong for this study.

The Research Grants Council supported G.K.K.C. by postdoctoral fellowship (reference no. PDFS2122-4H02). The US National Academy of Medicine supported R.Y.C. by International Health Policy fellowship.

\section{About the Author}

Dr. Chung is a postdoctoral fellow at the Chinese University of Hong Kong Institute of Health Equity. His research focuses primarily on how socioeconomic disadvantages (e.g., low education, poverty, and deprivation) affect population health and health inequalities from a life-course perspective.

\section{References}

1. Centre for Health Protection. Latest situation of cases of COVID-19 2020 [cited 2021 Feb 22]. https:/ / www.chp.gov. hk/files/pdf/local_situation_covid19_en.pdf

2. New Zealand Ministry of Health. COVID-19: source of cases [cited 2021 Feb 22]. https:/ / www.health.govt.nz/our-work/ diseases-and-conditions/covid-19-novel-coronavirus/covid19-data-and-statistics/covid-19-source-cases

3. Adam DC, Wu P, Wong JY, Lau EHY, Tsang TK, Cauchemez $S$, et al. Clustering and superspreading potential of SARS-CoV-2 infections in Hong Kong. Nat Med. 2020;26:1714-9. https://doi.org/10.1038/s41591-020-1092-0
4. Cordes J, Castro MC. Spatial analysis of COVID-19 clusters and contextual factors in New York City. Spat SpatioTemporal Epidemiol. 2020;34:100355. https:/ / doi. org/10.1016/j.sste.2020.100355

5. Office for National Statistics. Coronavirus (COVID-19) related deaths by occupation, England and Wales: deaths registered up to and including 20 April 2020. 2020 May 11 [cited 2021 Aug 13]. https://www.ons.gov.uk/ peoplepopulationandcommunity/healthandsocialcare/ causesofdeath/bulletins/coronaviruscovid19relateddeathsbyoccupationenglandandwales/deathsregistereduptoandincluding20april2020

6. Nicodemo C, Barzin S, Cavalli N, Lasserson D, Moscone F, Redding $\mathrm{S}$, et al. Measuring geographical disparities in England at the time of COVID-19: results using a composite indicator of population vulnerability. BMJ Open. 2020;10:e039749. https:/ / doi.org/10.1136/ bmjopen-2020-039749

7. Whittle RS, Diaz-Artiles A. An ecological study of socioeconomic predictors in detection of COVID-19 cases across neighborhoods in New York City. BMC Med. 2020;18:271. https:// doi.org/10.1186/s12916-020-01731-6

8. COVID-19 in HK. COVID-19 in HK [cited 2021 Feb 22]. https:/ / covid19.vote4.hk

9. Census and Statistics Department. 2016 Population by-census: statistics by large Tertiary Planning Unit group. 2017 [cited 2021 Feb 22]. https:/ / www.bycensus2016.gov. hk/en/bc-dp-tpu.html

10. Chung RY, Chung GK, Gordon D, Mak JK, Zhang LF, Chan D, et al. Housing affordability effects on physical and mental health: household survey in a population with the world's greatest housing affordability stress. J Epidemiol Community Health. 2020;74:164-72. https:/ / doi.org/10.1136/jech-2019-212286

11. Wang J, Huang B, Zhang T, Wong H, Huang Y. Impact of housing and community conditions on multidimensional health among middle- and low-income groups in Hong Kong. Int J Environ Res Public Health. 2018;15:1132. https:// doi.org/10.3390/ijerph15061132

12. Woo J. COVID-19 and residential care homes in Hong Kong. Jour Nursing Home Res. 2020;6:20-1. https:/ / doi.org/ 10.14283/jnhrs.2020.4

13. Burton JK, Bayne G, Evans C, Garbe F, Gorman D, Honhold N, et al. Evolution and effects of COVID-19 outbreaks in care homes: a population analysis in 189 care homes in one geographical region of the UK. Lancet Healthy Longev. 2020;1:e21-31. https:/ / doi.org/10.1016/ S2666-7568(20)30012-X

14. Chung GK, Dong D, Wong SY, Wong H, Chung RY. Perceived poverty and health, and their roles in the poverty-health vicious cycle: a qualitative study of major stakeholders in the healthcare setting in Hong Kong. Int J Equity Health. 2020;19:13. https:/ / doi.org/10.1186/ s12939-020-1127-7

15. Wong NS, Lee SS, Kwan TH, Yeoh E-K. Settings of virus exposure and their implications in the propagation of transmission networks in a COVID-19 outbreak. Lancet Reg Health West Pac. 2020;4:100052. https://doi.org/10.1016/ j.lanwpc.2020.100052

Address for correspondence: Roger Y. Chung, 4/F, School of Public Health and Primary Care, Prince of Wales Hospital, Shatin, NT, Hong Kong, China; email: rychung@cuhk.edu.hk 